\title{
Logística Integrada de Produção e Industrialização de Aves: O Caso da Seara Alimentos S.A.
}

\begin{abstract}
Alessandra Gallon
Doutorado em andamento em Engenharia de Produção pela Universidade Federal de Santa Catarina - UFSC

Professora do Centro Universitário Municipal de São José - USJ Universidade Federal de Santa Catarina (PPGEP). Florianópolis/SC. CEP: 88040-970

E-mail:alegallon@terra.com.br

Aloísio Grunow Mestrado em Ciências Contábeis pela Universidade Regional de Blumenau - FURB Professor da Faculdade Avançada do Ensino Superior - FAES Avenida Marginal Leste. Balneário Camburiu/SC. CEP: 88339-125

E-mail: agrunow@univali.br

Ilse Maria Beuren Doutorado em Controladoria e Contabilidade pela Universidade de São Paulo - USP Professora da Universidade Regional de Blumenau - FURB Rua Antonio Veiga, 104 (FURB/PPGCC). Blumenau/SC. CEP: 89012-900 E-mail: ilse@furb.br
\end{abstract}

\section{RESUMO}

Em um ambiente competitivo não basta coordenar e promover a eficiência das atividades internas da empresa, é necessário que as atividades que compõem a cadeia de valor sejam igualmente organizadas de forma competitiva. Neste sentido, o presente artigo descreve a logística integrada de produção e industrialização de aves, a partir dos pintainhos de 1 dia. Para tanto, realizou-se um estudo exploratório, por meio de um estudo de caso em uma agroindústria, com abordagem qualitativa dos dados. Como resultados da pesquisa tem-se a função de cada elemento na cadeia produtiva, cada fase do processo e a visualização completa da logística adotada. Conclui-se que uma adequada logística de produção e industrialização de aves pode proporcionar a melhoria do resultado global da empresa, uma vez que permite promover a redução de custos e o desenvolvimento de parcerias-chave.

Palavras-chave: Produção de aves. Industrialização de aves. Logística.

Logistics of Poultry Production and Industrialization by Seara Alimentos S.A. 


\section{ABSTRACT}

In a competitive environment, it is not enough to just coordinate and promote the efficiency of a company's internal activities. It is also necessary to ensure that a company's activities that form part of the "value chain" be organized in a competitive way. From this perspective, the objective of this article is to describe Seara Alimentos S.A's logistics of poultry production and industrialization from the first day the chicks are hatched. The methodology consisted of an exploratory research using a case study of an agro-industrial company with a qualitative approach to the data. The results of the research show every stage of the productive cycle, each phase of the process and the complete visualization of the logistics used. It was concluded that by having an adequate poultry production and industrialization logistics, a better global result for the company is produced, since this control allows the reduction of costs and the development of key partnerships.

Key Words: Poultry production. Poultry industrialization. Logistics.

\section{INTRODUÇÃO}

Com o aumento da competição entre as empresas nos mais diferentes setores de atuação, torna-se cada vez mais relevante ampliar a extensão do processo decisório além das fronteiras de cada organização. Nesta perspectiva, o gerenciamento da cadeia de suprimentos, de forma adequada, pode representar para a empresa uma vantagem competitiva em termos de qualidade e agilidade na prestação de serviços, redução de custos e velocidade de resposta às necessidades do mercado.

Chopra (2003) explica que a cadeia de suprimentos engloba todos os estágios envolvidos, direta ou indiretamente, no atendimento do pedido de um cliente. Ela não inclui apenas fabricantes e fornecedores, mas também transportadoras, depósitos, varejistas e os próprios clientes. Em cada organização a cadeia de suprimentos inclui todas as funções envolvidas no pedido do cliente, como desenvolvimento de novos produtos, marketing, operações, distribuição, finanças e o serviço de atendimento ao cliente.

A competição global evidencia a necessidade de maior agilidade, eficiência e segurança no fluxo de informações entre fabricantes e distribuidores, ao longo da cadeia de suprimentos. Conforme Heskett (1986, p. 159), "as organizações começaram a se dar conta de que uma chave para manter a lucratividade a longo prazo é maior 
interdependência". As tecnologias da informação logística, nesse contexto, desempenham papel primordial, pois permitem coligir, com segurança, cada vez maior volume de dados, reduzir custos de tratamento de dados e eliminar as barreiras das distâncias geográficas.

Jacobsen (2003) afirma que o objetivo fundamental da logística é atender adequadamente o consumidor final, administrando globalmente a empresa e seus agentes logísticos externos, através de um processo de gestão integrado, cooperativo e harmonioso de negócios, que vai desde os fornecedores, almoxarifado, fábrica, depósito de produtos acabados, centros de distribuição, atacadistas, varejistas, até os consumidores finais.

$\mathrm{Na}$ nova concepção de cadeia varejista, de acordo com Novaes (2004), todo o processo logístico, que vai da matéria-prima até o consumidor final, é hoje considerado entidade única, sistêmica, em que cada parte do sistema depende das demais e deve ser ajustado visando o todo em busca da satisfação do cliente.

Pires (2004, p. 63) destaca a importância da "consciência do papel fundamental da logística no escopo da gestão da cadeia de suprimentos e da necessidade de conhecer melhor a gestão da cadeia de suprimentos como um todo para poder realizar os processos logísticos de forma efetiva e adequada".

Diante do exposto, o objetivo deste artigo é descrever a logística integrada de produção e industrialização de aves, a partir dos pintainhos de 1 dia. Buscou-se verificar a atuação coordenada do frigorífico, a agregação de valor por parte dos elos antecedentes e o processo criterioso de seleção de parceiros e formação de alianças estratégicas.

A relevância da pesquisa evidencia-se na medida em que se observa um mercado cada vez mais dinâmico e competitivo, no qual a automação dos processos ultrapassou as fronteiras da empresa para avançar nas relações entre fornecedores, indústria e clientes. A verificação empírica do que é preconizado na teoria pode contribuir para sedimentar conceitos já consagrados, bem como conduzir à novas formulações teóricas. 


\section{GERENCIAMENTO DA CADEIA DE VALOR}

Uma vez que a empresa interage constantemente com o ambiente, deve orientar-se para a busca da interação com o meio que a cerca. Gibbon (2002) destaca que o contexto de uma cadeia produtiva, que possa agregar valor em toda sua extensão, com o intuito de proporcionar o máximo de satisfação ao cliente final, é imprescindível nos dias atuais.

As cadeias de valor são integradas por vários participantes, entrando e conduzindo acordos mutuamente benéficos de longo prazo. Tais acordos são conhecidos por diversos nomes: parcerias, alianças estratégicas, terceirizações e contratos logísticos (Miranda, 2002).

De acordo com Lambert, Stock e Vantine (1998, p. 35), "o número de alianças ou parcerias está aumentando todos os anos na medida que as empresas reconhecem os benefícios mútuos que podem advir de um trabalho em conjunto ao invés de independentemente".

Porter (1990) menciona que a extensão da integração nas atividades desempenha uma função-chave na vantagem competitiva, uma vez que as atividades na cadeia de valor de uma empresa estão ligadas entre si e às outras atividades de seus fornecedores, canais e compradores. Estes elos afetam a vantagem competitiva global da cadeia. Nesse sentido, Shank e Govindarajan (1997, p. 59) ressaltam que "cada empresa deve ser entendida no contexto da cadeia global das atividades geradoras de valor da qual ela é apenas uma parte".

A empresa deve estabelecer vantagens competitivas sustentáveis para permanecer ou alcançar novos mercados, mas para isso ela deve compreender o ambiente em que se encontra. Porter (1990) cita que a cadeia de valor de uma empresa e o modo como ela executa suas atividades individuais são reflexos de sua história, de sua estratégia, do método de implementação de sua estratégia e da economia básica das próprias atividades.

De forma restrita, Miranda (2002) define a cadeia de produção como o conjunto de atividades executadas para produzir e entregar um produto ou serviço aos consumidores finais. Esse conjunto de atividades inclui desde a produção ou extração 
de matérias-primas, seu processamento, transporte, armazenamento e distribuição, até a sua entrega aos consumidores.

No contexto da cadeia de valor, Gibbon (2002) relata que uma estrutura organizacional planejada e coordenada, visando inter-relações entre atividades similares, fluxo de informações, relacionamentos com fornecedores e com canais de distribuição, que possa romper com a fronteira interna da empresa e que promova a integração de seus elos verticais, são fatores de vital importância para o sucesso da estratégia empresarial.

A Figura 1 apresenta um modelo de cadeia de valor, mostrando a interação da empresa com seus elos antecedentes e subseqüentes, em que o fluxo de informações, produtos e fundos, entre todos os integrantes da cadeia, ocorre nos dois sentidos.

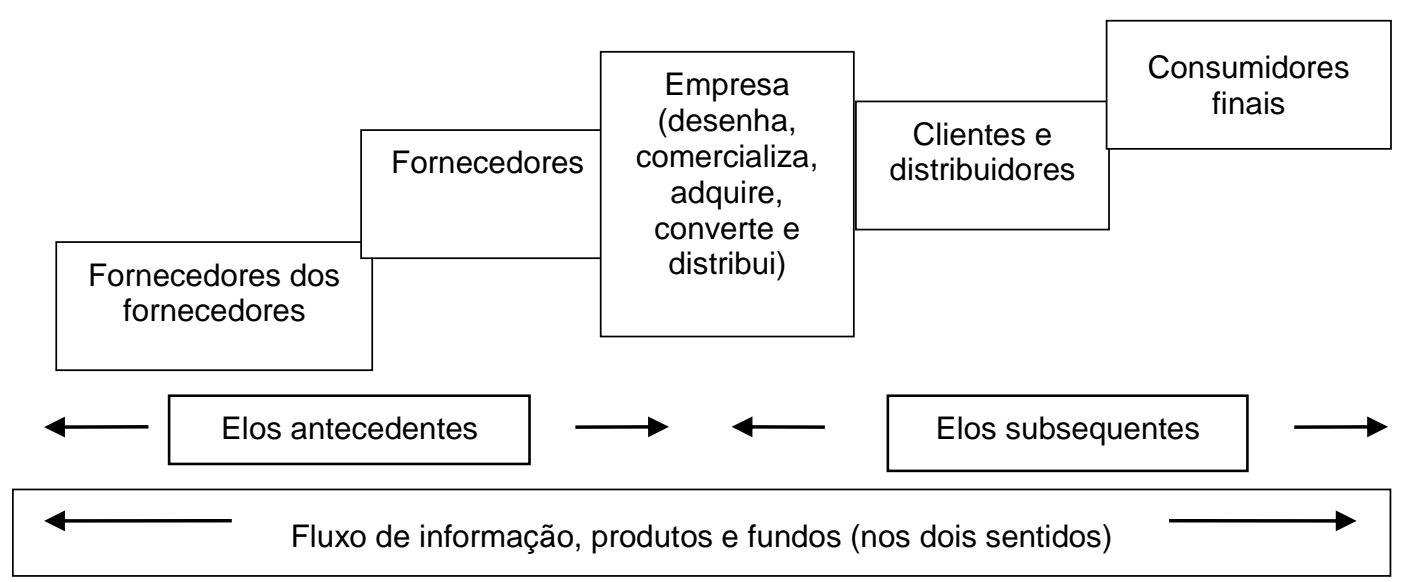

Figura 1 - Modelo de cadeia de valor

Fonte: adaptada de Miranda (2002, p. 203)

Nota-se na Figura 1 a importância de considerar todos os participantes relevantes dos elos que executam as atividades que antecedem (elos antecedentes) e que complementam (elos subseqüentes) às atividades executadas pela empresa. Quanto mais estreito o relacionamento entre os integrantes da cadeia de valor, maiores são as chances que as habilidades de cada integrante sejam aplicadas em benefício próprio. 
A noção espacial da cadeia de valor é externa à empresa, sendo esta apenas uma parte do todo. Os resultados podem ser obtidos por meio da estreita relação entre os integrantes da cadeia, com otimização global dos custos e de desempenho, tornando-os mais significativos do que a soma dos possíveis ganhos individuais de cada integrante, quando atuam separadamente.

Nesse contexto evidencia-se a necessidade de gerenciar a cadeia de valor com visão holística e não apenas dentro dos limites de cada empresa. Ao longo da cadeia de valor é imperativo gerenciar adequadamente os processos dos negócios-chave que ocorrem entre as empresas integrantes da cadeia.

O gerenciamento da cadeia de valor reconhece que a integração interna de uma empresa não é suficiente, pois fazem parte do seu contexto as interações da empresa com seus parceiros, concorrentes, fornecedores e clientes. De acordo com Ching (1999), está se tornando evidente a necessidade de estender a lógica da integração para fora das fronteiras da empresa para incluir fornecedores e clientes.

O procedimento normalmente utilizado para a implementação de princípios de integração de sistemas é conhecido como reengenharia de processos. De acordo com Hammer e Champy (1994), a reengenharia é o repensar fundamental e a reestruturação radical dos processos empresariais que visam alcançar drásticas melhorias em indicadores críticos e contemporâneos de desempenho, tais como custo, qualidade, atendimento e velocidade. A idéia básica é identificar e estudar as fases necessárias para executar um trabalho específico de modo a aumentar a possibilidade de integração do desempenho.

Para satisfazer aos objetivos básicos da sobrevivência, todas as partes da empresa devem funcionar como uma grande unidade, ou seja, devem estar interligadas. A visão da empresa como sistema integrado de ações direcionadas para metas proporciona o máximo impacto competitivo.

Ching (1999) destaca que há uma corrida em andamento para a integralização da cadeia logística. Está se tornando clarividente a necessidade de estender a lógica da integração para fora das fronteiras da empresa visando incluir fornecedores e clientes.

De acordo com Novaes (2004), a moderna logística procura incorporar: 
a) prazos previamente acertados e cumpridos integralmente, ao longo de toda a cadeia de suprimentos;

b) integração efetiva e sistêmica entre todos os setores da empresa;

c) integração efetiva e estreita (parcerias) com fornecedores e clientes;

d) busca da otimização global, envolvendo a racionalização dos processos e a redução de custos em toda a cadeia de suprimentos; e

e) satisfação plena do cliente, mantendo nível de serviço preestabelecido e adequado.

A partir da criação de parcerias, segundo Ching (1999, p. 64), as empresas buscam "otimizar as oportunidades de negócio e fechar os elos com os clientes e com os Fornecedores". Nota-se que é imprescindível a adoção de conceitos de logística integrada para o gerenciamento da cadeia de valor. As empresas não podem mais concentrar a gestão considerando cada uma de forma isolada, mas vislumbrar a integração da cadeia logística.

\section{LOGÍSTICA INTEGRADA}

Logística é difinida por Bowersox, Closs e Helferich (1986, p. 3) como "um sistema lógico para guiar o processo de planejamento, alocação e controle de recursos financeiros e humanos comprometidos com a distribuição física, dando suporte às operações de produção e de compras".

De acordo com o Conselho de Administração da Logística (apud PIZZOLATO, 2000), logística é o processo de planejamento, implementação e controle do fluxo eficiente e economicamente eficaz de matérias-primas, estoque em processo, produtos acabados e informações relativas, desde o ponto de origem até o ponto de consumo, com o propósito de atender às exigências do cliente.

Segundo o Instituto IMAM (2000, p. 1), a logística é "o processo que integra, coordena e controla: a movimentação de materiais, inventário de produtos acabados e informações relacionadas; dos fornecedores através de uma empresa; para satisfazer as necessidades dos clientes". Bowersox e Closs $(1996$, p. 5) destacam que a "a 
responsabilidade operacional da logística é o posicionamento dos estoques, de matérias-primas, produtos em processos e produtos acabados, onde requeridos, ao mais baixo custo possível".

Novaes (2004) adota a definição do Council of Logistics Management norteamericano, qual seja, "logística é o processo de planejar, implementar e controlar de maneira eficiente o fluxo e a armazenagem de produtos, bem como os serviços e informações associados, cobrindo desde o ponto de origem até o ponto de consumo, com o objetivo de atender aos requisitos do consumidor".

Como se pode observar nestas definições, a logística não deve ser entendida somente como distribuição física de produtos aos clientes. Em sentido mais amplo, ela se preocupa com a oferta dos bens e serviços por parte das empresas aos clientes. Além disso, é necessário que a logística seja concebida como uma atividade de suporte em todos os campos, para incrementar e solidificar o resultado dos negócios da empresa.

Ching (1999) destaca a necessidade de integralização da cadeia logística, na medida em que se faz necessário estender a lógica da integração para além das fronteiras da empresa, incluindo fornecedores e clientes. Além disso, todas as partes da empresa devem funcionar como uma unidade, ou seja, seus departamentos devem estar interligados. A visão da empresa como sistema integrado, com ações direcionadas para o cumprimento das metas, proporciona maior impacto competitivo.

O procedimento normalmente utilizado para a implementação de princípios de integração de sistemas é conhecido como reengenharia de processos. A idéia básica é identificar e estudar as fases necessárias para executar um trabalho específico, de modo a aumentar a possibilidade de integração do desempenho.

A logística empresarial, para Ballou (1993), trata de todas as atividades de movimentação e armazenagem que facilitam o fluxo de produtos, desde o ponto de aquisição da matéria-prima até o ponto do consumidor final, assim como dos fluxos de informação que colocam os produtos em movimento, com o propósito de providenciar níveis de serviço adequados aos clientes a um custo razoável. 
A Figura 2 destaca o processo logístico, ressaltando os fluxos de informação e de materiais e a função da logística no gerenciamento dos fluxos.

Fluxo de informação
Função
Fluxo de materiais

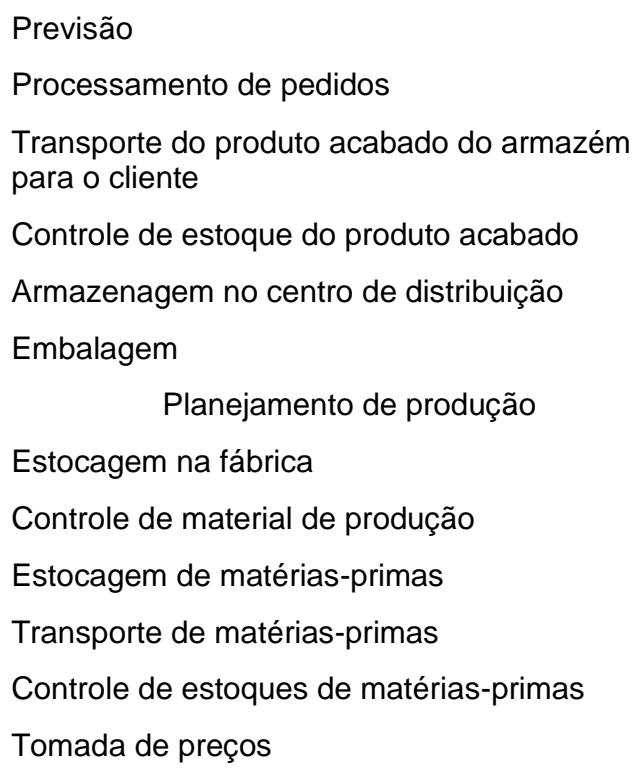

Figura 2 - O processo da logística Fonte: adaptada de Heskett (1986, p. 10)

Depreende-se da Figura 2 que o processo ou gerenciamento da logística é o meio pelo qual as necessidades dos clientes são satisfeitas mediante a coordenação dos fluxos de materiais e de informações, que vão do mercado até a empresa, suas operações e, posteriormente, para seus fornecedores. Heskestt (1986, p. 10) ressalta que o objetivo básico do gerenciamento logístico "é fornecer um nível desejado de serviços aos clientes a um custo aceitável à empresa". 
Martin (1997, p. 10) ressalta que "a missão do gerenciamento logístico é planejar e coordenar todas as atividades necessárias para alcançar níveis desejáveis dos serviços e qualidade ao custo mais baixo possível". Dessa forma, a logística integrada pode ser entendida como o elo entre o mercado e a atividade operacional da empresa, visando satisfazer as necessidades dos clientes a um custo razoável.

\section{MÉTODO E PROCEDIMENTO DA PESQUISA}

O método empregado na presente pesquisa é de natureza exploratória, realizada por meio de um estudo de caso, com abordagem qualitativa. Para Cervo e Bervian (1996), a pesquisa exploratória "é responsável por observar, registrar, analisar e correlacionar os fatos ou fenômenos sem manipulá-los".

O estudo de caso foi intensivo em uma agroindústria, cuja denominação social é Seara Alimentos S.A., compreendendo fenômenos da sua logística integrada em relação ao objeto de estudo. Yin (2003, p. 21) observa que o estudo de caso permite

uma investigação para se preservar as características holísticas e significativas dos eventos da vida real - tais como ciclos de vida individuais, processos organizacionais, administrativos, mudanças ocorridas em regiões urbanas, relações internacionais e a maturação de alguns setores.

Os dados foram coletados na empresa de duas formas: em arquivos internos e por meio da técnica de observação. Fachin (2001, p. 35) adverte que "o observador deve reunir certas condições, entre as quais dispor dos órgãos sensoriais em perfeito estado, de um bom preparo intelectual, aliado à sagacidade, curiosidade, persistência, perseverança, paciência e um grau elevado de humildade".

Para a coleta de ambas as fontes de dados foram seguidas as etapas propostas por Yin (2003) no protocolo para condução de estudos de caso: 
- Procedimentos de campo (credenciais e acesso aos locais do estudo de caso, fontes gerais de informações e advertências de procedimentos).

- Questões do estudo de caso (as questões específicas que o pesquisador do estudo de caso deve manter em mente ao coletar os dados, uma planilha para disposição específica de dados e as fontes em potencial de informações ao se responder cada questão).

- Guia para o relatório do estudo de caso (resumo, formato de narrativa e especificação de quaisquer informações bibliográficas e outras documentações).

$\mathrm{Na}$ análise dos dados utilizou-se a abordagem qualitativa. Richardson (1989, p. 39) explica que "as investigações que se voltam para uma análise qualitativa têm como objeto situações complexas ou estritamente particulares".

Os resultados da pesquisa limitam-se ao caso estudado, uma vez que se escolheu como estratégia de pesquisa estudar somente uma agroindústria. Também não foi aplicado um instrumento de pesquisa aos responsáveis pela logística integrada na empresa estudo de caso, restringindo-se à análise documental e técnica de observação.

\section{DESCRIÇÃO DA LOGÍsticA INTEGRAdA DE PRODUÇÃo E INDUSTRIALIZAÇÃO DA EMPRESA OBJETO DE ESTUDO}

Para a compreensão da logística integrada da produção e industrialização de aves, realizou-se um estudo das operações na empresa Seara Alimentos S.A., com sede em Itajaí/SC. Busca-se mostrar todos os passos da logística de industrialização de uma ave para abate, desde a chegada dos pintainhos de 1 dia, até a entrega, por meio de transportadores terceirizados, aos clientes finais no Brasil e no exterior.

A Seara Alimentos S.A. é uma agroindústria, pertencente ao grupo Cargill, que produz, abate e industrializa carnes de aves e suínos. A empresa tem 4 abatedouros de aves em Santa Catarina, 1 abatedouro de aves no Paraná, 1 abatedouro de aves em Mato Grosso do Sul e 1 abatedouro de aves em São Paulo. São abatidas 22,5 milhões 
de cabeças de aves por mês em suas 7 fábricas, gera 15.000 empregos diretos e mantêm negócios com 2.300 produtores integrados.

Ocupa a terceira posição no país, no segmento de aves e carnes processadas, com forte presença na linha de produtos cortados e desossados de frango, destacandose como líder na exportação de frangos em cortes. Ocupa a posição de vice-líder nas exportações de carne suína (carcaças e cortes), e, no mercado interno, concentra seu potencial em carnes processadas, por meio das linhas de presuntos, lingüiças, salsichas, empanados e outras. Em 2004 foi lançada a linha de pratos prontos, incrementando seu portfólio de produtos de maior valor agregado.

Para compreensão da logística integrada de produção e industrialização, apresentam-se três fluxos de operações. Primeiro demonstram-se as operações que vão da chegada dos pintainhos de 1 dia até a entrega das aves prontas para abate na plataforma de abate. No segundo fluxo evidenciam-se as operações que vão do abate das aves até a produção da carcaça de aves limpas e prontas para corte. No terceiro fluxo são mostradas as operações que vão do corte das aves, passando pela padronização, embalagem, armazenagem e entrega do produto para o cliente final.

Não foi abordada nesse estudo a fase de produção dos pintainhos de 1 dia, pois o objetivo do artigo é mostrar a logística integrada e as fases da cadeia produtiva de aves, a partir do pintainho de 1 dia.

\subsection{Pintainhos de 1 dia até a produção de aves de corte para abate}

Primeiramente apresenta-se a interligação entre as etapas internas e externas à empresa do processo de produção das aves de corte para o abate. Este processo ocorre junto às granjas de produtores terminadores integrados. Levam-se em consideração a quantidade, peso, tempo de produção, sanidade, bem-estar animal, condenações, medicamentos, conforme se ilustra na Figura 3. 


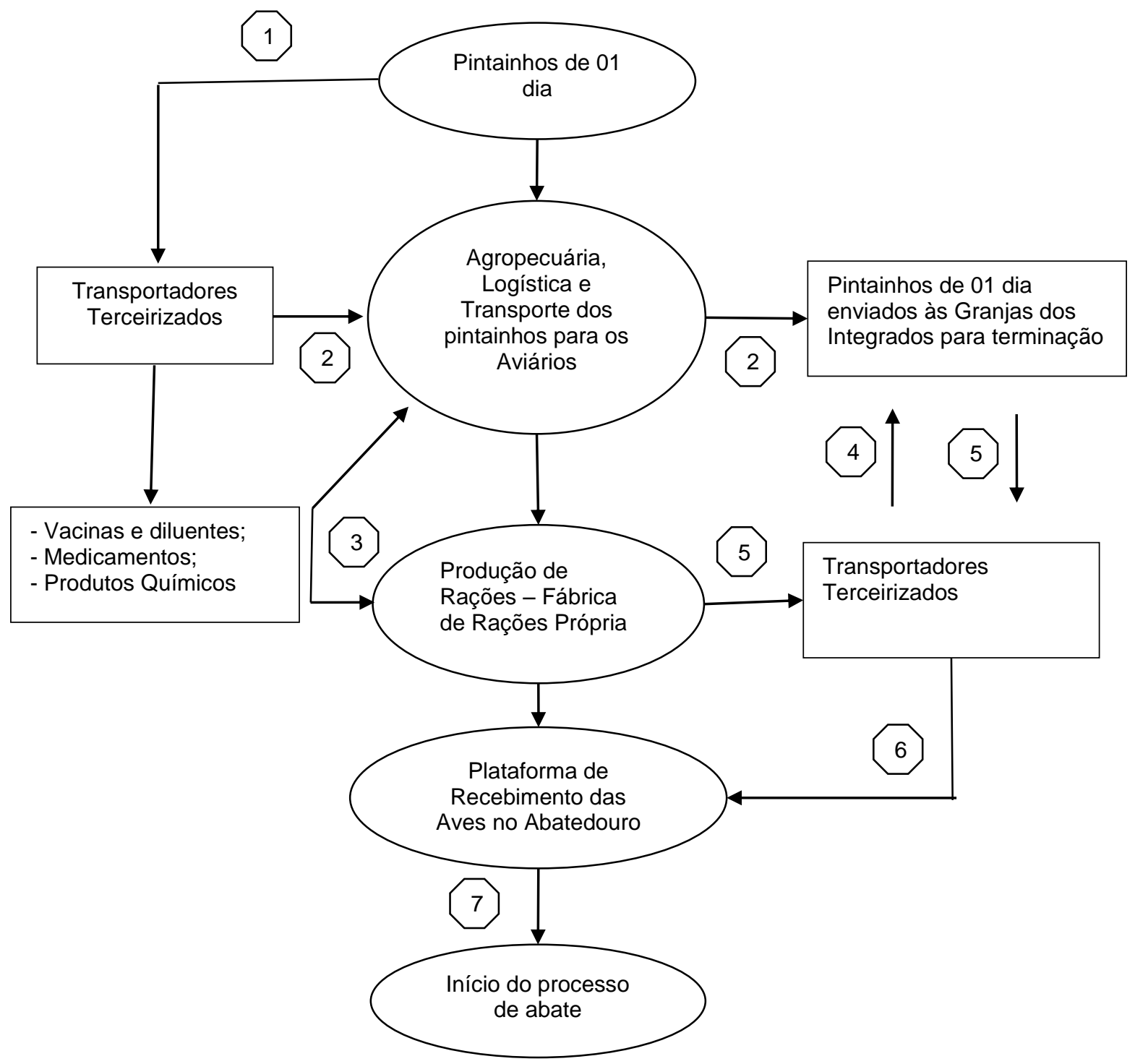

Figura 3 - Fluxo dos pintainhos de 1 dia até a produção de aves de corte para abate Fonte: dados da pesquisa

O fluxo compreende desde o pintainho de 1 dia até a ave estar pronta para 0 abate. Cada uma das operações que compõem esta etapa da produção é descrita na seqüência:

a) Operações 1 e 2 - os pintainhos de 1 dia são transferidos das incubadoras para serem alojados nos produtores integrados, em caminhões especiais climatizados (25 
C) terceirizados. Estes pintainhos ficam em média 45 dias alojados nestas granjas até atingir o peso de abate (1,8 kgs até $2,5 \mathrm{kgs})$;

b) Operações 3 e 4 - após o envio dos pintainhos de 1 dia para os integrados, a Seara Alimentos S.A. envia as rações produzidas em suas fábricas de rações, por meio de caminhões graneleiros terceirizados. As rações são produzidas de acordo com o plantel a ser alimentado, rações para matrizes, machos e rações para aves de corte. Além das rações, a Seara Alimentos S.A. também adquire de fornecedores os medicamentos e vacinas, que são aplicados nos animais alojados nas granjas. $O$ produtor tem responsabilidade pela aquisição da maravalha, descarregar os pintainhos de 1 dia, carregar as aves terminadas, mão-de-obra para o trato, limpeza e desinfecção, controle integrado de pragas, energia elétrica, água, gás ou lenha e outros;

c) Operações 5 e 6 - após o período de crescimento das aves, que dura de 38 a 45 dias, as mesmas são colocadas pelos produtores integrados e seus auxiliares em gaiolas plásticas (média de 8 cabeças em cada caixa), após são colocadas sobre os caminhões terceirizados, que fazem o transporte até a plataforma de abate;

d) Operação 7 - quando as aves chegam na plataforma de abate é encerrado o processo de produção da matéria-prima viva, isto é, todos os custos de produção já estão embutidos nos animais vivos, inclusive a remuneração do parceiro produtor. A produção da matéria-prima é a principal responsabilidade do departamento agropecuário da Seara Alimentos S.A. As aves são descarregadas e ficam aguardando o início do processo de abate.

A criação de frango de corte é realizada em sistema de parceria. A Seara Alimentos S.A. fornece os pintainhos de 1 dia, ração, assistência técnica, transporte e quando aplicável, medicamentos, desinfetantes, raticidas e inseticidas. É de responsabilidade dos parceiros a aquisição de maravalha, gastos relacionados com criação e carregamento das aves vivas, tais como mão-de-obra para o trato, limpeza e desinfecção, controle integrado de pragas, energia elétrica, água, gás ou lenhas e, quando aplicável, a utilização de desinfetantes e medicamentos recomendados pela Seara Alimentos S.A. 
É de responsabilidade da equipe técnica da Seara Alimentos S.A. a orientação aos parceiros quanto à criação das aves, no que diz respeito às instalações, manejos, condições sanitárias e meio ambiente. São fornecidas Orientações Técnicas (OT's) a cada parceiro, sendo que as visitas técnicas acontecem conforme necessidade identificada pela equipe técnica ou solicitação do parceiro.

A partir do alojamento dos pintainhos são geradas informações da data provável de abate, de acordo com o histórico de cada produtor. Essas informações são confirmadas, na periodicidade definida previamente pelo gestor do processo, por meio de dados de peso e mortalidade passadas pelos produtores, fornecidos por telefone e/ou palm top.

A Seara Alimentos S.A. mantém um rigoroso controle sanitário dos plantéis, incluindo toda cadeia produtiva: granja de matrizes, incubatórios próprios e terceirizados e aves de corte. Esse controle engloba ações quando são observadas anomalias como: sinais de doenças, mortalidade elevada e outros. Os resultados laboratoriais de swab de arrasto e o monitoramento também são realizados pelos técnicos durante as visitas. As avaliações, diagnósticos e prescrições dos técnicos podem ser evidenciadas por meio da ficha de acompanhamento do lote ou programa $\mathrm{M}$ Tech.

Quando os animais chegam na plataforma de abate é realizada a avaliação das aves de corte, no abatedouro, quanto aos seguintes itens: mortalidade no transporte, papo cheio, pele riscada, condenações, calo, entre outros. A finalidade é identificar a qualidade das aves. É preciso melhorar continuamente o FEP (Fator de Eficiência de Produção). A cada fechamento de lote é analisado, pelo gestor do processo, o desempenho dos parceiros, com base em indicadores de desempenho de peso, conversão alimentar e mortalidade.

O acompanhamento dos técnicos de agropecuária tem a finalidade de realizar a avaliação constante dos resultados de desempenho do lote atual e/ou anteriores. A partir dessa avaliação prescrevem orientações na Ficha de Acompanhamento do Lote, além de gerar ações de melhoria, corretiva e preventiva, se for o caso. Quando detectada a necessidade de alteração de algum item de manejo de criação de aves, 0 
assunto é discutido com o gestor do processo que avalia a situação, podendo solicitar a revisão das orientações técnicas ou mesmo iniciar um processo de teste via PDA (Projeto e Desenvolvimento Agropecuário).

\subsection{Processo de Industrialização na Agroindústria}

Concluída a fase de produção das aves para abate, o próximo passo é o processo de industrialização dentro do abatedouro, que vai da plataforma de abate até a embalagem, armazenagem e distribuição para os clientes no mercado interno e mercado internacional. Na Figura 4 evidencia-se a primeira etapa da industrialização de aves, que vai do abate das aves até a produção da carcaça de aves limpas e prontas para corte.

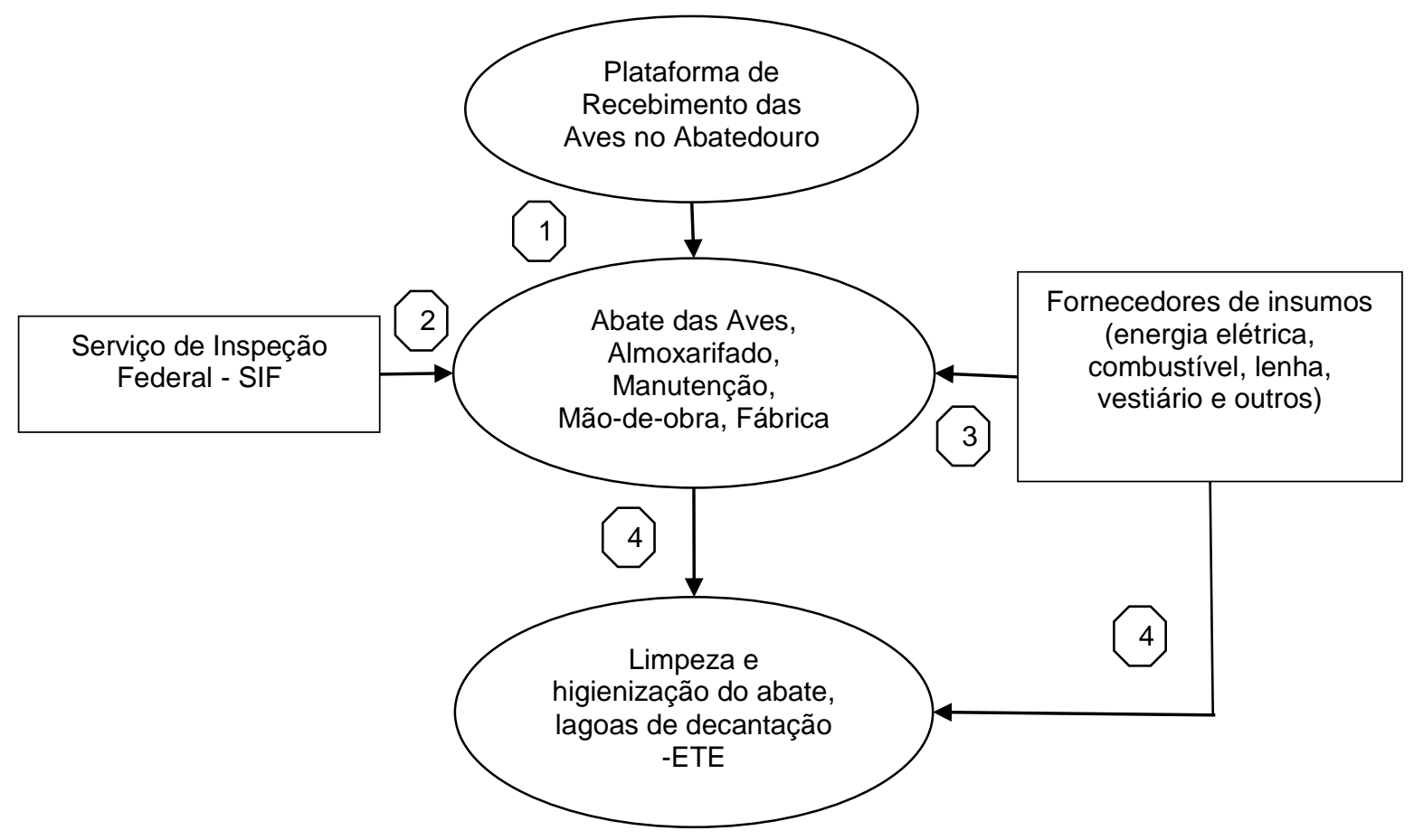

Figura 4 - Fluxo relacionado ao abate de aves Fonte: dados da pesquisa

Nesta etapa as aves vivas são abatidas e preparadas para serem cortadas em partes, originando os produtos derivados de acordo com os pedidos dos clientes no 
Brasil e no exterior. Na seqüência descrevem-se as operações compreendidas nesta etapa:

a) Operações 1 e 3 - as aves vivas, que estão na plataforma de abate, são transferidas para a sala de abate, onde é feita a sangria, escaldagem, depenação, limpeza, evisceração, separação e limpeza dos miúdos, com utilização de insumos fornecidos por terceiros e também próprios, originando como produto, nesta fase, a carcaça completa eviscerada e limpa. Para realizar estas atividades são necessárias as áreas de apoio, tais como portaria, almoxarifado, manutenção, laboratório, casa de máquinas, instalações térmicas, fábrica de farinhas e óleos, serviços de tratamento de água, entre outros;

b) Operação 2 - as operações de abate são acompanhadas integralmente pela equipe de veterinários e ajudantes do Serviço de Inspeção Federal;

c) Operação 4 - após o encerramento do abate é realizada a higienização da sala de abate, com produtos adquiridos de fornecedores. Nesta fase também é efetuado o tratamento de efluentes e o processamento das vísceras, penas e resíduos na FFO (Fábrica de Farinhas e Óleos) e a limpeza final das carcaças das aves abatidas.

Após o término da primeira etapa da industrialização, que compreende 0 abate das aves, ocorre a segunda etapa deste processo na agroindústria. Na Figura 5 mostrase, ainda no processo de industrialização na agroindústria, a segunda etapa, que vai desde o corte das aves até a entrega do produto ao cliente final.

$\mathrm{Na}$ sequência descrevem-se as operações compreendidas nesta segunda etapa do processo de industrialização das aves na agroindústria:

a) Operação 1 - durante o processo de abate e corte ocorre a supervisão e o acompanhamento gerencial de todas as operações, além do controle da qualidade. Após o abate, inicia-se o processo de corte e separação das aves em partes, de acordo com pedidos dos clientes;

b) Operação 2 - após encerrado o processo de corte é realizada a padronização do peso dos produtos, embalagem e envio para congelamento. Os produtos resfriados são transferidos para estocagem nas câmaras de produtos resfriados; 
c) Operações 3 e 4 - nestas fases termina o processo produtivo, isto é, os produtos estão prontos para serem entregues aos clientes. Inicia-se a logística de distribuição, por meio dos transportadores terceirizados, com a finalidade de entregar os produtos para os clientes.

Como se pode observar, o processo de produção e industrialização de aves envolve a indústria (abatedouro), fornecedores, transportadores, os parceiros integrados, até os clientes/consumidores dos produtos, conforme abordado da revisão de literatura sobre cadeia de valor e logística integrada. 


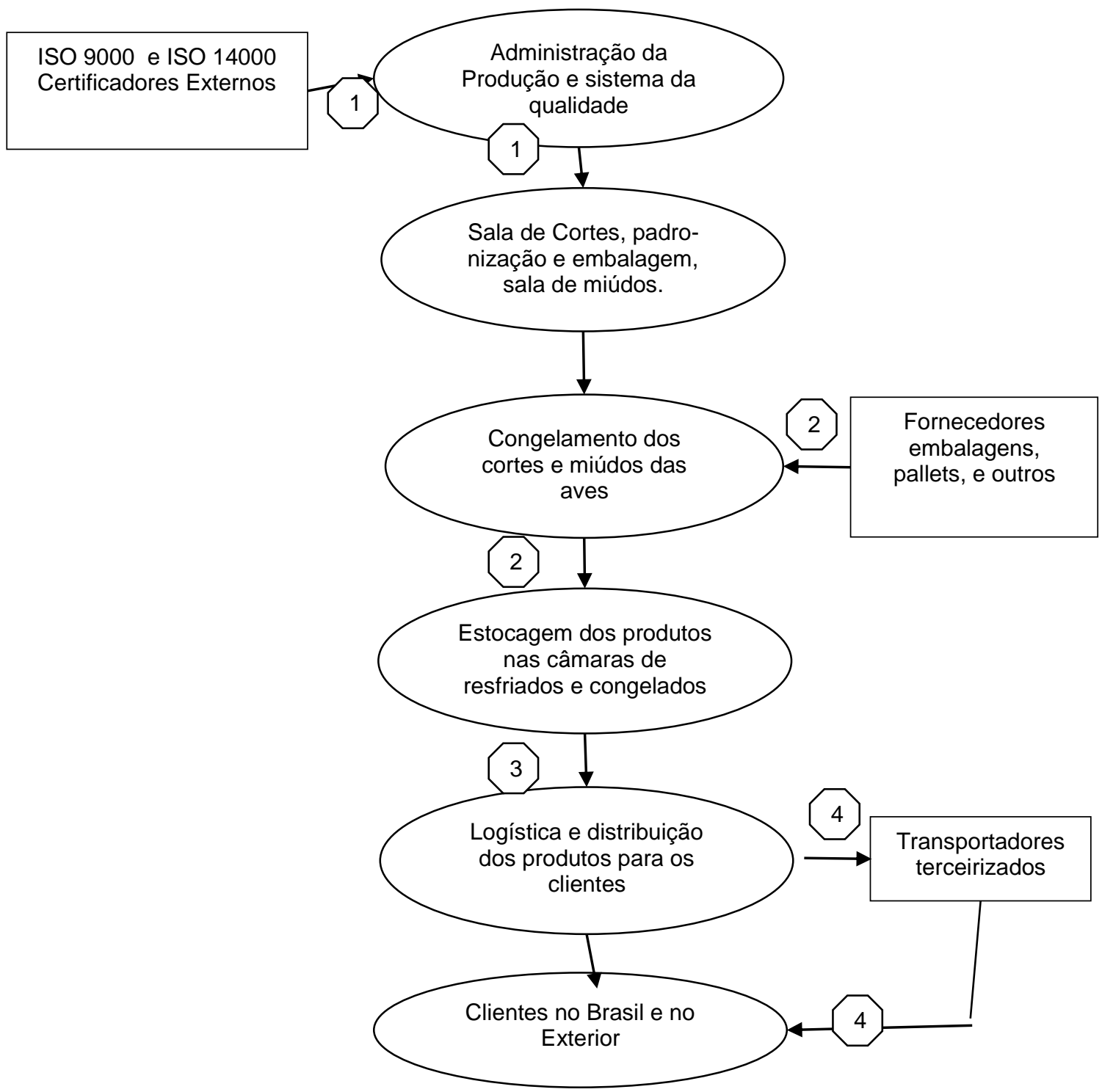

Figura 5- Fluxo relacionado ao corte de aves

Fonte: dados da pesquisa

\section{CONCLUSÕES}

O presente artigo objetivou descrever a logística integrada de produção e industrialização de aves, a partir dos pintainhos de 1 dia. Para tanto, realizou-se um estudo exploratório, mediante um estudo de caso em uma agroindústria e com abordagem qualitativa dos dados.

A logística integrada de produção e industrialização foi segmentada em três fluxos de operações. Primeiro demonstraram-se as operações que vão da chegada dos 
pintainhos de 1 dia até a entrega das aves prontas para abate na plataforma de abate. No segundo fluxo evidenciaram-se as operações que vão do abate das aves até a produção da carcaça de aves limpas e prontas para corte. No terceiro fluxo foram mostradas as operações que vão do corte das aves, passando pela padronização, embalagem, armazenagem e entrega do produto para o cliente final.

No estudo realizado na empresa Seara Alimentos S.A., observou-se a importância dos parceiros integrados. A logística integrada da empresa com os produtores de aves, se bem gerenciada e controlada, pode resultar em maior qualidade da matéria-prima e economias de custo aos integrantes da cadeia de valor, o que por si só já justifica uma atuação conjunta, aumentando também a competitividade global no mercado.

Em se tratando da industrialização de aves da Seara Alimentos S.A., verificou-se que a cadeia de valor interna da empresa é ampla e em cada fase do processo vai sendo agregado valor, mas em contrapartida incorrem-se em custos. Para assegurar a competitividade no mercado, a cadeia completa precisa ser gerenciada, considerandose cada parte, mas sempre numa perspectiva holística.

$O$ relacionamento entre os agentes da cadeia de valor requer transparência e uma relação interdependente. Porém, todos devem estar focados no mesmo objetivo, que é produzir com baixo custo para se manter nos mercados já existentes e desenvolver novos mercados. Na pesquisa realizada ficou evidenciada a importância de cada elo da cadeia produtiva, que vai desde o envio dos pintainhos de 1 dia até a entrega do produto final aos consumidores. Se um elo da cadeia não funcionar, compromete as demais fases do processo, trazendo perda para todos.

Outro ponto que se destaca é a participação do departamento agropecuário na orientação aos parceiros produtores quanto à criação de aves, especialmente no que diz respeito às instalações, manejos, condições sanitárias e meio ambiente. Este acompanhamento ocorre através das Orientações Técnicas (OT's) a cada parceiro

Conclui-se que a logística integrada de produção e industrialização de aves na Seara Alimentos S.A. é imprescindível devido a dependência das diversas etapas. No processo de produção, as diversas fases possuem uma seqüência lógica; sem ter 
cumprido a anterior não haverá a seguinte. Por sua vez, o processo de industrialização tem total dependência da produção de aves, uma vez que esta é sua fornecedora de matéria-prima.

Como resultados da pesquisa tem-se a descrição da logística integrada de produção e industrialização de aves, a partir dos pintainhos de 1 dia, ao longo da cadeia de valor da produção de aves da Seara Alimentos S. A. No entanto, levantam-se indagações que podem ser objeto de outras pesquisas sobre o tema, dada a relevância deste setor na economia do País.

Algumas das questões são: A configuração das etapas do ciclo produtivo ao longo da cadeia de valor da produção de aves é semelhante a apresentada em outras empresas do setor? A gestão da logística integrada de produção e industrialização de aves, a partir dos pintainhos de 1 dia, se reflete em maior competitividade para a agroindústria? As economias de custos pretendidas com a gestão da logística integrada de produção e industrialização de aves ocorrem na empresa pesquisada e se reproduzem em outras empresas do setor?

\section{REFERÊNCIAS}

BALLOU, Ronald H. (1993). Logística empresarial: transportes, administração de materiais e distribuição física. São Paulo, Atlas.

BOWERSOX, Donald J.; CLOSS, David J.; HELFERICH, Osmar K. (1986). Logistical management: a systems integration of physical distribution, manufacturing support, and materials procurement. New York: Macmillan.

BOWERSOX, Donald J.; CLOSS, David J. (1996). Logistical management: the integrated supply chain process. New York: McGraw-Hill.

CERVO, Amado Luiz; BERVIAN, Pedro Alcino. (1996). Metodologia científica. (4 ed.). São Paulo: Makron Books.

CHING, Hong Yuh. (1999). Gestão de estoques na cadeia de logística integrada. São Paulo: Atlas.

CHOPRA, Sunil; MEINDL, Peter. (2003). Gerenciamento da cadeia de suprimentos. São Paulo: Prentice Hall. 
FACHIN, Odília. (2001). Fundamentos de metodologia. São Paulo: Saraiva.

GIBBON, A.R. (2002). O. A gestão estratégica de custos de suprimento na perspectiva da cadeia de valor: o caso de uma empresa da indústria têxtil. 155 f. (Dissertação de Mestrado). Universidade Federal de Santa Catarina - UFSC. Florianópolis.

HAMMER, M.; CHAMPY, J. (1994). Reengenharia: revolucionando a empresa em função dos clientes, da concorrência e das grandes mudanças da gerência. (7 ed.). Rio de Janeiro: Campus.

HESKETT, James L. (1986). Logística: essencial para a estratégia. Coleção Harvard de Administração n. 15. São Paulo: Nova Cultural.

INSTITUTO IMAM. (2000). Gerenciamento da logística e cadeia de abastecimento. IMAM (Org.). São Paulo: IMAM.

JACOBSEN, Mércio. (2003). Logística empresarial. Itajaí: Univali.

LAMBERT, Douglas M.; STOCK, James R.; VANTINE, José Geraldo. (1998). Administração estratégica da logística. São Paulo: Vantine Consultoria.

MARTIN, Christopher. (1997). Logística e gerenciamento da cadeia de suprimentos: estratégias para a redução de custos e melhoria dos serviços. São Paulo: Pioneira.

MIRANDA, L. C. (2002). Gerenciamento da cadeia de valor. In: SCHMIDT, Paulo (Org.). Controladoria: agregando valor para a empresa. Porto Alegre: Bookman.

NOVAES, Antônio Galvão. (2004). Logística e gerenciamento da cadeia de distribuição: estratégia, operação e avaliação. (2 ed). Rio de Janeiro: Elsevier.

PIRES, Sílvio R. I. (2004). Gestão da cadeia de suprimentos: conceitos, estratégias, práticas e casos. São Paulo: Atlas.

PIZZOLATO, Nélio Domingues. (2000). Introdução à contabilidade gerencial. (2 ed.). São Paulo: Makron Books.

PORTER, Michael E. (1990). Vantagem competitiva: criando e sustentando um desempenho superior. Rio de Janeiro: Campus.

RICHARDSON, Roberto Jarry. (1999). Pesquisa social: métodos e técnicas. (3 ed.). São Paulo: Atlas.

SHANK, John K.; GOVINDARAJAN, Vijay. (1997). A revolução dos custos: como reinventar e redefinir sua estratégia de custos para vencer em mercados crescentemente competitivos. (2 ed.). Rio de Janeiro: Campus. 
Logística Integrada de Produção e Industrialização de Aves: O Caso da Seara Alimentos S.A. Alessandra Gallon, Aloísio Grunow, Ilse Maria Beuren

YIN, Robert K. (2003). Estudo de caso: planejamento e métodos. São Paulo, Bookman, reimpressão.

Data de Submissão: 21/03/2008

Data de Aceite: 23/04/2009 